\title{
BIOPSY IN COELIAC DISEASE DIAGNOSIS: WHEN IS IT NECESSARY?
}

\author{
Tuccio A., Boddi G., Iurato C., Nanni S., Vascotto M., Balestri P.
}

\section{U.O.C. Pediatria, Dipartimento Materno-Infantile, A.O.U. Santa Maria Le Scotte, Siena, Italy}

\begin{abstract}
Duodenal biopsy is considered the Gold Standard for Coeliac Disease (CD) diagnosis at the moment. As the ESPGHAN guidelines published in 2012 state, CD can be diagnosed without biopsy in patients with typical symptoms and tTG-IgA levels which are ten times over the reference values. The aim of this study is to establish the association between tTG-IgA levels and anatomic lesions, by redefining the biopsy role in the CD diagnosis. The research focuses on Positive Predictive Value of serological tests, also in patients without typical clinical presentation. In this retrospective study, clinical and laboratory data have been analysed in 95 pediatric patients, assessed at the Pediatric Unit in Siena from 2005 to 2011. Eightysix patients have been included, with typical symptoms, monosymptomatic or asymptomatic, all with tTG-IgA >9U/ml and a biopsy report. Patients have been divided into 5 groups (A-E) according to their tTG-IgA levels: A, >100 UI/ml; B, 8099 UI/ml; C, 60-79 UI/ml; D, 40-69 UI/ml; E, 9-39 UI/ml. A Positive Predictive Value (PPV) for each group has been evaluated. 78,9 of the patients included reported a positive biopsy. Biopsy was positive in 100 of the patients in groups A, B, C, with a Positive Predictive Value of $100 \%$. PPV was $75 \%$ in group D and 78,7\% in group E. In group A patients were divided in 3 subgroups: typical symptoms $(67.4 \%)$, monosymptomatic $(16.2 \%)$ and asymptomatic $(16.2 \%)$. All of them (100\%) had a positive biopsy report. PPV was $100 \%$ in typical symptoms subgroup as well as in monosymptomatic and asymptomatic patients. This study confirms the ESPGHAN Recommendation, concluding that in patients with typical symptoms and tTg-IgA ten times over the reference values the biopsy could be avoided. These results open the question whether the biopsy can be also avoided in patients with tTG-IgA ten times over the reference values even if monosymptomatic or asymptomatic. This approach could be followed by $50 \%$ of biopsies avoided in our case series.
\end{abstract}

\section{INTRODUCTION}

The European Society of Gastroenterology, Hepatology and Nutrition (ESPGHAN) defines Celiac Disease (CD) as an immune-mediated systemic disorder elicited by gluten and related prolamines, developed in genetically susceptible individuals and characterised by the presence of a variable combination of gluten-dependent clinical manifestations, CD-specific antibodies, HLA-DQ2 or HLA-DQ8 haplotypes, and enteropathy [1]. CD prevalence is $1 \%$ at the moment, even if it is often not diagnosed because of aspecific or minimal symptoms [2]. The disease is associated with Human Leukocyte Antigen (HLA) DQAl*0501 e DQB1*0201 in $90 \%$ of patients. Among affected patients, over $97 \%$ has marker HLA-DQ2 and/or HLADQ8, while in general population only 30-40\% has this aplotype. A genetic susceptibility is also shown by the fact that $2-5 \%$ of $1^{\text {st }}$-degree relatives has symptomatic gluten-dependent enteropathy and $10 \%$ of $1^{\text {st }}$ degree relatives shows asymptomatic intestinal mucosal lesions, compatible with CD. Moreover, there are other CD-related genes, which do not belong to HLA complex. Groups with a major risk of CD can be children affected with diabetes mellitus I, Down syndrome, Turner syndrome, Williams syndrome, autoimmune thyroiditis and IgA deficit. Autoimmune disease prevalence is higher in CD patients rather than in general population, on the contrary, CD develops more frequently in patients with other known autoimmune diseases [3].

CD clinical presentation comprehends a wide range of signs and symptoms, but it can also be asymptomatic. Diagnosis is extremely important not only in children with classical symptoms but also in monosymptomatic or asymptomatic, because it is demonstrated that a diagnostic delay can be related to higher morbility and short stature in adult age [4].

Symptoms can be divided in two groups:

a. Gastrointestinal (more common in children $<2$ years): chronic diarrhea, chronic constipation, abdominal pain, nausea, vomiting, distended abdomen;

b. Extraintestinal: failure-to-thrive, stunted growth, delayed puberty, chronic anaemia (the most com-

\section{Correspondence to:}

Alessandra Tuccio

University of Siena. Polyclinic "Le Scotte", Viale Bracci, 53100 Siena, Italy.

Telephone number: +39.0577 .586547 .

E-mail: aletuccio@hotmail.it 
mon among extraintestinal symptoms), decreased bone mineralization (osteopenia/osteoporosis), dental enamel defects, irritability, chronic fatigue, neuropathy, arthritis/arthralgia, amenorrhea, increased levels of liver enzymes [5].

Diagnostic tests firstly consist in measuring antibodies tTG-IgA (anti-tissutal transglutaminase) and EMA (anti-endomysium). EMA binds connectival tissue that envelops smooth muscle. This test is highly specific for celiac disease, even if with low title. Sensitivity is $>90 \%$ and specificity is almost $100 \%$. Tissutal transglutaminase is an intestinal epithelium enzyme that catalyses glutamine deamination. It is the target of EMA. IgA anti-tTG has a sensitivity of $\mathbf{9 0 - 9 8 \%}$ and a specificity of $\mathbf{9 4 - 9 8 \%}$. Intestinal biopsy is defined as the gold standard for diagnosis, as claimed in NICE guidelines, National Institute for Clinical Evidence [6]. Anatomic lesions are classified according to MarshOberhuber classification (1999) (Table 1) and, more recently, Corazza-Villanacci one (2005) (Table 2) [7,8].

Anyway, considering the invasive character of both the endoscopic procedure and the anaesthesia, the high cost of this practice and, at the same, time keeping into account the higher and higher CD prevalence, less invasive diagnostic tests are being tried [9]. Since the sensitivity and specificity of serological tests are reaching the values of $100 \%$, it is necessary to understand in which conditions they can be used as exclusive tools for diagnosis [2]. There are increasing evidence that diagnosis can be assessed without biopsy in pediatric patients with tTG-IgA > 10 times over reference values and typical symptoms [10,11]. The ESPGHAN Recommendation (2012) states that: “Histological assessment may be omitted in symptomatic patients who have high IgA anti-TG2 levels (10 times above reference values), verified by EMA positivity, and are HLA-DQ2 and/or HLA-DQ8 heterodimer positive" [1].

The aim of the study is to establish the association between tTG-IgA levels and anatomic lesions, by redefining the biopsy role in CD diagnosis. The research focuses on Positive Predictive Value of serological tests, even in children without typical clinical presentation.

\section{METHODS}

In this retrospective study, clinical and laboratory data have been analysed in 95 pediatric patients, assessed at the Pediatric Unit in Siena from 2005 to 2011. 86 patients have been included, with tTG-IgA $>9 \mathrm{U} / \mathrm{ml}$ and a biopsy report. They were 62 females and 24 males, mean age was 6,86. 9 patients have been excluded because they had not undergone an EGDS. Biopsy report has been considered positive if the

Table 1. Marsh-Oberhuber Classification (IEL = intraepithelial lymphocytes, reference values: $<40$ in jejunum and $<30$ in duodenum).

\begin{tabular}{lcccc}
\hline Marsh type & $\begin{array}{c}\text { IEL/Enterocytes } \\
\text { jejunum }\end{array}$ & $\begin{array}{c}\text { IEL/Enterocytes } \\
\text { duodenum }\end{array}$ & Crypt hyperplasia & Villi \\
\hline $\mathbf{0}$ & $<40$ & $<30$ & Normal & Normal \\
\hline $\mathbf{1}$ & $>40$ & $>30$ & Normal & Normal \\
\hline $\mathbf{2}$ & $>40$ & $>30$ & Increased & Normal \\
\hline $\mathbf{3}^{\circ}$ & $>40$ & $>30$ & Increased & Mild atrophy \\
\hline $3 \mathbf{b}$ & $>40$ & $>30$ & Increased & Marked atrophy \\
\hline $3 \mathbf{c}$ & $>40$ & $>30$ & increased & Complete atrophy \\
\hline
\end{tabular}

Table 2. Corazza-Villanacci Classification.

\begin{tabular}{ll}
\hline Grading & \\
\hline A & Non atrophic lesion \\
\hline B & Atrophic lesion \\
& B $1-$ Villous/Crypt ratio $<3 / 1$, with still detectable villi \\
& B2 - Not still detectable villi \\
\hline
\end{tabular}


anatomic lesion was $\geq 2$ in Marsh-Oberhuber Classification. Patients have been divided into 5 groups (A-E), see Table 3, according to their tTG-IgA levels and a Positive Predictive Value (PPV) for each group has been evaluated.

There were 43 patients in group A. They were divided in 3 subgroups, according to their presentation phenotype:

a. typical symptoms $(67.4 \%) n=29$;

b. monosymptomatic $(16.2 \%) n=7$;

c. asymptomatic $(16.2 \%) n=7$.

Children in typical symptoms subgroup (a) presented 2 or more of these features: diarrhea, abdominal pain, malabsorption, sideropenic anaemia, failure to thrive.

In monosymptomatic subgroup (b): 4 patients had failure to thrive, 2 had sideropenic anemia and 1 of them had fractures and vitamine $\mathrm{D}$ deficit.

In asymptomatic children (c) tTG-IgA were positive during screening for positive family history $(n=2)$, for atopic dermatitis $(n=2)$ or occasional test $(n=3)$.

\section{RESULTS}

Among 86 patients included in our study, $78,9 \%$ had a positive biopsy report. Biopsy was positive in all patients in group A, B and C (Table 4).

The Positive Predictive Value of serological tests was $100 \%$ in patients with $\mathrm{tTg}-\mathrm{IgA}>60 \mathrm{UI} / \mathrm{ml}$. This predictive value can also be applied in patients with tTG-IgA $>100 \mathrm{UI} / \mathrm{ml}$ and atypical symptomatology or monosymptomatic. Biopsy report was positive in 3 out of 4 patients in group D and in 26 out of 33 patients in group E with a PPV respectively of $75 \%$ e $78.7 \%$ (Table 5).

\section{CONCLUSIONS}

In our research, those patients with tTG-IgA $>100$ $\mathrm{UI} / \mathrm{ml}$ and typical symptoms were 29: according to ESPGHAN guidelines, biopsy could be avoided in 29 out of 86 studied cases, therefore in $33.7 \%$ (i.e. one third of our case-series). This retrospective study demonstrates that CD diagnosis can be assessed without biopsy at least in children with typical symptoms, tTG-IgA > $100 \mathrm{UI} / \mathrm{ml}$ and positive EMA. A prudent but feasible approach could be renouncing to intestinal biopsy only if tTG-IgA positivity is associated with

Table 3. Patients have been divided into 5 groups, according to their tTG-IgA values.

\begin{tabular}{lc}
\hline Groups & $\begin{array}{c}\text { Ttg-IgA levels } \\
(\mathrm{UI} / \mathrm{ml})\end{array}$ \\
\hline $\mathrm{A}(n=43)$ & $>100$ \\
\hline $\mathrm{B}(n=5)$ & $80-99$ \\
\hline $\mathrm{C}(n=1)$ & $60-79$ \\
\hline $\mathrm{D}(n=4)$ & $40-59$ \\
\hline $\mathrm{E}(n=33)$ & $9-39$ \\
\hline
\end{tabular}

Table 4. Clinical features and positive biopsy reports for each group.

\begin{tabular}{|c|c|c|c|}
\hline Group & Serology tTg-IgA (UI/ml) & Clinical features & Biopsy $\geq$ Marsh 2 \\
\hline \multirow[t]{3}{*}{$A(n=43)$} & $>100$ & Typical $(n=29)$ & $29 / 29$ \\
\hline & & Monosymptomatic $(n=7)$ & $7 / 7$ \\
\hline & & Asymptomatic $(n=7) 7 / 7$ & \\
\hline \multirow[t]{3}{*}{$B(n=5)$} & $80-99$ & Typical $(n=1)$ & $1 / 1$ \\
\hline & & Monosymptomatic $(n=2)$ & $2 / 2$ \\
\hline & & Asymptomatic $(n=2)$ & $2 / 2$ \\
\hline \multirow[t]{3}{*}{$C(n=1)$} & $60-79$ & Typical $(n=1)$ & $1 / 1$ \\
\hline & & Monosymptomatic & - \\
\hline & & Asymptomatic & - \\
\hline \multirow[t]{3}{*}{$D(n=4)$} & $40-59$ & Typical $(n=1)$ & $1 / 1$ \\
\hline & & Monosymptomatic $(n=3)$ & $2 / 3$ \\
\hline & & Asymptomatic & - \\
\hline \multirow[t]{3}{*}{$E(n=33)$} & $9-39$ & Typical $(\mathrm{n}=22)$ & $17 / 22$ \\
\hline & & Monosymptomatic $(\mathrm{n}=4)$ & $4 / 4$ \\
\hline & & Asymptomatic $(n=7)$ & $5 / 7$ \\
\hline
\end{tabular}


Table 5. Biopsy report and Positive Predictive values has been calculated for each group.

\begin{tabular}{lcc}
\hline Groups & Positive biopsy & PPV (\%) \\
\hline $\mathrm{A}(n=43)$ & 43 & 100 \\
\hline $\mathrm{B}(n=5)$ & 5 & 100 \\
\hline $\mathrm{C}(n=1)$ & 1 & 100 \\
\hline $\mathrm{D}(n=4)$ & 3 & 75 \\
\hline $\mathrm{E}(n=33)$ & 26 & 78.7 \\
\hline
\end{tabular}

EMA positivity and the genetical compatibility is confirmed. This approach is also suggested by ESPGHAN guidelines.

In despite of the small case-series, $32.4 \%$ of group A $(n=14$, i.e. almost one third) does not have classical symptoms, while it presents tTG-IgA $>100 \mathrm{UI} / \mathrm{ml}$ and positive biopsy report. To conclude, following ESPGHAN guidelines, out of 86 patients of our caseseries, 29 with typical symptoms could have been diagnosed without biopsy. Nevertheless, according to our research, the previously studied 14 children (monosymptomatic or asymptomatic) could also have been diagnosed without biopsy. Therefore, a total of 43 children $(50 \%$ of the case-series) could have avoided biopsy procedure.

There is still room for verifying the effects of this new indications in clinical practice: will the diagnosis procedure have a further simplification or will it become more complicated? Finally, will exams, advices and patient's complaints before diagnosis increase or decrease? There will be more mistakes? Which will be the effect of the diagnosis without biopsy on the gluten-free diet compliance? All these questions will need to be answered by ad hoc studies. Nevertheless, evidence still shows a need of simplifying CD diagnosis, due to its high prevalence. The real effectiveness of this new approach and its effects on CD management will need to be addressed by further multicenter prospective studies.

\section{REFERENCES}

1. Husby, S.; Koletzko, S.; Korponay-Szabo', R.; Mearin, M. L.; Phillips, A.; Shamir, R.; Troncone, R.; Giersiepen, R.; Branski, D.; Catassi, C.; Lelgeman, M.; Maki, M.; Ribes-Koninckx, C.; Ventura,
A.; Zimmer, K. P.; for the ESPGHAN Working Group on Coeliac Disease Diagnosis, on behalf of the ESPGHAN Gastroenterology Committee. European Society for Pediatric Gastroenterology, Hepatology, and Nutrition Guidelines for the Diagnosis of Coeliac Disease. J. Pediatr. Gastroenterol. Nutr. 54: 136-160; 2012.

2. Mubarak, A.; Wolters, V. M.; Gerritsen, S. A. M.; Gmelig-Meyling, F. H. J.; Ten Kate, F. J. W.; Houwen, R. H. J. A biopsy is not always necessary to diagnose celiac disease. J. Pediatr. Gastroenterol. Nutr. 52: 554-557; 2011.

3. Kurppa, K.; Salminiemi, J.; Ukkola, A.; Saavalainen, P.; Löytynoja, K.; Laurila, K.; Collin, P.; Mäki, M.; Kaukinen, K. Utility of the new ESPGHAN criteria for the diagnosis of celiac disease in at-risk groups. J. Pediatr. Gastroenterol. Nutr. 54: 387-91; 2012.

4. Freeman, H. J.; Chopra, A.; Clandinin, M. T.; Thomson, A. B. R. Recent advances in celiac disease. World J. Gastroenterol. 17: 2259$2272 ; 2011$.

5. Troncone, R.; Jabri, B. Coeliac disease and gluten sensitivity. Journal of Internal Medicine. 269: 582-590; 2011.

6. National Institute for Clinical Excellence. Clinical Guideline 86: coeliac disease. http://www.nice.org.uk/nicemedia/pdf/CG86FullGuideline.pdf.

7. Oberhuber, G.; Granditsch, G.; Vogelsang, H. The histopatology of coeliac disease: time for a standardized report scheme of pathologists. Eur. J. Gastroenterol. Hepatol. 11: 1185-1194; 1999.

8. Corazza, G. R.; Villanacci, V.; Zambelli, C.; Milione, M.; Luinetti, O.; Vindigni, C.; Chioda, C.; Albarello, L.; Bartolini, D.; Donato, F. Comparison of interobserver reproducibility with different histologic criteria used in celiac disease. Clin. Gastroenterol. Hepatol. 5: 838-843; 2007.

9. Giersiepen, K.; Lelgemann, M.; Stuhldreher, N.; Ronfani, L.; Husby, S.; Koletzko, S.; Korponay-Szabó, I. R.; ESPGHAN Working Group on Coeliac Disease Diagnosis. Accuracy of diagnostic antibody tests for coeliac disease in children: summary of an evidence report. J. Pediatr. Gastroenterol. Nutr. 54: 229-241. 2012.

10. Benelli, E.; Ronfani, L.; Radillo, O.; Martelossi, S.; Ventura, A. Diagnosi di celiachia: basta con la biopsia? Medico e Bambino. 8: 493-498; 2002.

11. Hill, I. D.; Horvath, K. Non biopsy diagnosis of celiac disease: are we nearly there yet? J. Pediatr. Gastroenterol. Nutr. 54: 310-1; 2012. 